\title{
PENGARUH PENDEKATAN PEMBELAJARAN KONTEKSTUAL BERBASIS BERPIKIR KRITIS TERHADAP HASIL BELAJAR SEJARAH DI SMK NEGERI 1 LUBUK PAKAM
}

\author{
Asriyeni' ${ }^{1}$, Samsidar Tanjung2 \\ 1) Alumni Jurusan Pendidikan Sejarah, Universitas Negeri Medan, Indonesia \\ 2) Jurusan Pendidikan Sejarah, Universitas Negeri Medan, Indonesia \\ Corresponding Email: asriyeni01@gmail.com
}

\begin{abstract}
This study aims to determine the effect of using a contextual approach based on critical thinking on the learning outcomes of the history of students at SMK Negeri 1 Lubuk Pakam, Deli Serdang Regency. This study used a quasi-experimental method with the design of the two group pretest-posttest design. The study population was all students of class X majoring in Teknik Komputer Jaringan (TKJ) and class X majoring in Rekayasa Perangkat Lunak (RPL), amounting to 143 students, with a study sample of 72 students consisting of 36 students of class $X$ TKJ-B as an experimental class and 36 students of class $X$ RPL as a control class. Data collection uses the test method. The test results show that the average value of TKJ-B class $X$ students who take part in learning with a critical thinking based contextual approach is 85.28 , while the average value of RPL class X students who follow learning with conventional models is 72.64. Hypothesis testing uses the $t$-test that shows $t_{\text {count }}>t_{\text {table }}$ with a value of $t_{\text {count }}$ at 7.14 and the value of $t_{\text {table }}$ is 1.668. Based on the results of the study it was found that there were significant differences between student learning outcomes that followed learning with contextual approaches and historical learning outcomes of students who followed learning with conventional models. Student learning outcomes using a contextual approach are better than the student's learning outcomes with conventional learning models.
\end{abstract}

Keywords: Contextual Approach, Critical Thinking, Learning Outcomes

\begin{abstract}
Abstrak
Penelitian ini bertujuan untuk mengetahui pengaruh penggunaan pendekatan kontekstual berbasis berpikir kritis terhadap hasil belajar sejarah siswa di SMK Negeri 1 Lubuk Pakam, Kabupaten Deli Serdang. Penelitian ini menggunakan metode eksperimen semu dengan desain penelitian two group pretest-posttest design. Populasi penelitian adalah seluruh siswa kelas X jurusan Teknik Komputer Jaringan (TKJ) dan kelas X jurusan Rekayasa Perangkat Lunak (RPL) yang berjumlah 143 siswa, dengan sampel penelitian 72 siswa yang terdiri dari 36 siswa kelas X TKJ-B sebagai kelas eksperimen dan 36 orang siswa kelas X RPL sebagai kelas kontrol. Pengumpulan data menggunakan metode tes. Hasil tes menunjukkan bahwa nilai rata-rata siswa kelas X TKJ-B yang mengikuti pembelajaran dengan pendekatan kontekstual berbasis berpikir kritis sebesar 85,28, sedangkan nilai rata-rata siswa kelas X RPL yang mengikuti pembelajaran dengan model konvensional sebesar 72,64. Pengujian hipotesis menggunakan uji-t yang menunjukkan $t_{\text {hitung }}>t_{\text {tabel }}$ dengan nilai $t_{\text {hitung }}$ sebesar 7,14 dan nilai $t_{\text {tabel }}$ sebesar 1,668. Berdasarkan hasil penelitian diketahui adanya perbedaan yang signifikan antara hasil belajar siswa yang mengikuti pembelajaran dengan pendekatan kontekstual dan hasil belajar sejarah siswa yang mengikuti pembelajaran dengan model konvensional. Hasil belajar siswa dengan menggunakan pendekatan kontekstual lebih baik dibandingkan dengan hasil belajar siswa dengan model pembelajaran konvensional.
\end{abstract}

Kata Kunci: Pendekatan Kontekstual, Berpikir Kritis, Hasil Belajar 


\section{PENDAHULUAN}

Pembelajaran sejarah di sekolah memiliki peran penting dalam menanamkan prinsip-prinsip moral, menumbuhkan sensitivitas terhadap berbagai permasalahan masyarakat, mumupuk sikap toleransi dan memperkokoh semangat nasionalisme (Kochhar, 2008: 31-36). Dengan mempelajari sejarah, siswa dapat mengambil nilai-nilai penting dari peristiwa-peristiwa masa lalu yang bisa dijadikan sebagai pedoman dan inspirasi untuk menjalani kehidupan masa kini dan merencanakan masa depan (Isjoni, 2007).

Akan tetapi, pembelajaran sejarah yang saat ini berlangsung di banyak sekolah cenderung kering dan membosankan. Hal ini terjadi karena guru-guru sejarah masih memakai paradigma konvensional dalam mengelola kegiatan pembelajaran. Guru dengan paradigma konvensional hanya menggunakan metode ceramah dalam proses pembelajaran sehingga menjadikannya sebagai sumber informasi di kelas. Sementara itu, siswa hanya mendengarkan penjelasan guru, mencatat dan menghafal peristiwaperistiwa masa lalu. Proses pembelajaran seperti ini pada akhirnya memunculkan anggapan bahwa mata pelajaran sejarah hanya pelajaran hafalan, bahkan dianggap mata pelajaran yang kurang penting (Ali, 2005: 1).

Salah satu sekolah yang menerapkan paradigma konvensional dalam proses pembelajaran sejarah adalah Sekolah Menengah Kejuruan (SMK) Negeri 1 Lubuk Pakam, Kabupaten Deli Serdang. Hasil observasi penulis menunjukkan bahwa guru-guru yang mengampu mata pelajaran sejarah di sekolah tersebut bukan dari bidang ilmu pendidikan sejarah, melainkan dari pendidikan tata niaga, pendidikan ekonomi dan pendidikan Pancasila dan Kewarganegaraan. Dalam kegiatan pembelajaran di kelas, mereka hanya menggunakan metode ceramah sehingga pembelajaran tidak berjalan efektif. Bahkan cara mereka mengajar di kelas dinilai kurang baik oleh siswa.

Berdasarkan wawancara penulis dengan siswa kelas $\mathrm{X}$ jurusan Teknik Kompoter Jari- ngan dan siswa kelas $\mathrm{X}$ jurusan Rekayasa Perangkat Lunak diperoleh informasi bahwa kegiatan pembelajaran sejarah di kelas hanya didominasi oleh guru, sedangkan siswa hanya dituntut untuk mendengar, mencatat dan menghafal. Kegiatan pembelajaran seperti ini membuat pelajaran sejarah kurang diminati oleh siswa. Bahkan sebagian besar siswa berpendapat bahwa mata pelajaran sejarah tidak begitu penting bagi mereka. Alasannya karena pelajaran sejarah hanya berorientasi masa lalu dan tidak ada hubungannya dengan jurusan mereka.

Menurut Subakti (2010), kegiatan pembelajaran sejarah yang kaku, kering dan membosankan akan berakibat buruk untuk jangka waktu yang panjang dan berpotensi memunculkan generasi yang "buta sejarah" bangsanya. Oleh karena itu, guru sejarah harus menanggalkan paradigma konvensional, kemudian beralih ke paradigma siswa aktif dalam mengelola pembelajaran di kelas. Paradigma baru ini menuntut guru sejarah untuk mampu menerapkan model dan metode pembelajaran yang inovatif agar siswa terlibat aktif dalam proses pembelajaran.

Pelajaran sejarah merupakan pelajaran tiga dimensi, yaitu pelajaran yang membahas masa lalu, masa sekarang dan masa depan. Oleh karenanya, guru sejarah dituntut untuk tidak hanya menjelaskan kejadian-kejadian masa lalu, tetapi juga harus mampu mengaitkannya dengan kehidupan sehari-hari siswa. Pembelajaran sejarah dengan pendekatan kontekstual akan menumbuhkan kesadaran siswa bahwa pembelajaran sejarah bukan hanya tentang masa lalu, tetapi juga berkaitan dengan masa kini dan masa depan. Model pembelajaran kontekstual dapat meningkatkan minat siswa untuk belajar sejarah karena mereka terlibat langsung dalam proses pembelajaran. Dengan begitu, hasil belajar sejarah siswa juga akan meningkat.

Pembelajaran sejarah dengan pendekatan kontekstual dapat membuat siswa belajar mengalami, bukan menghafal. Siswa akan terlibat aktif dalam proses pembelajaran karena mereka 
dituntut untuk membangun sendiri pengetahuannya melalui kegiatan tanya jawab. Metode tanya jawab menjadi strategi untuk menggali keingintahuan siswa. Selain itu, keberadaan kelompok belajar menjadi nilai lebih karena siswa tidak belajar sendiri, tetapi saling bekerjasama melalui belajar kelompok agar pemahaman siswa lebih mendalam.

Penerapan pendekatan kontekstual dalam pembelajaran sejarah dapat melatih siswa berpikir kritis karena siswa dituntut untuk mengaitkan materi pelajaran dengan kehidupan sehari-hari mereka. Menurut Fisher (2009: 13), berpikir kritis adalah aktivitas terampil yang bisa dilakukan dengan lebih baik atau sebaliknya, dan pemikiran kritis yang baik akan memenuhi beragam sumber-sumber informasi lainnya. Melatih siswa untuk berpikir kritis dapat dilakukan dengan memberi pertanyaan atau soal. Dalam mencermati soal, siswa dituntut untuk memahaminya dalam penerapan di kehidupan sehari-hari. Dengan melatih siswa untuk berpikir kritis dalam proses pembelajaran, maka hasil belajar sejarah mereka akan meningkat. Bahkan kebiasaan berpikir kritis sangat bemanfaat bagi siswa untuk mencermati berbagai persoalan yang hadir dalam kehidupan mereka.

Berdasarkan latar belakang di atas, pokok permasalahan yang hendak dikaji dalam penelitian ini adalah pengaruh pendekatan kontekstual terhadap hasil belajar siswa di kelas X SMK Negeri 1 Lubuk Pakam. Kajian ini diharapkan menjadi inspirasi bagi guru-guru sejarah agar dapat menerapkan model pembelajaran kontekstual dalam kegiatan belajar mengajar di kelas supaya siswa memperoleh hasil belajar yang maksimal.

\section{METODE PENELITIAN}

Kajian ini menggunakan metode penelitian kuantitatif dengan jenis eksperimen semu (quasi eksperimen). Eksperimen semu yang dimaksud dalam penelitian ini adalah pengontrolan variabel hanya dilakukan terhadap satu variabel yang dipandang paling dominan (Sukmadinata, 2013:
59). Sementara itu, desain penelitian yang digunakan adalah two group pretest-posttest design. Tes diberikan sebanyak dua kali, yaitu penerapan pendekatan pembelajaran kontekstual terhadap kelas eksperimen dan perlakukan biasa terhadap kelas kontrol.

Penelitian dilakukan di SMK Negeri 1 Lubuk Pakam yang terletak di Kabupaten Deli Serdang, Propinsi Sumatera Utara. Subjek penelitian adalah siswa kelas $\mathrm{X}$ jurusan Teknik Komputer Jaringan (TKJ) yang terbagi dalam tiga kelas, dan siswa kelas $\mathrm{X}$ jurusan Rekayasa Perangkat Lunak (RPL) yang hanya satu kelas. Jumlah keseluruhan siswa di dua jurusan itu mencapai 143 orang. Pengambilan sampel dilakukan secara random sampling. Hasilnya, sampel untuk kelas eksperimen jatuh pada siswa kelas X TKJ-B yang berjumlah 36 siswa, sedangkan sampel untuk kelas kontrol adalah siswa kelas X RPL yang berjumlah 36 siswa.

Adapun instrumen tes hasil belajar siswa yang disusun oleh penulis dapat dilihat pada table 1. Pengujian validitas soal menggunakan rumus koefesien korelasi biserial. Validitas setiap soal ditentukan dengan kriteria makin tinggi koefisien korelasi yang dimiliki, maka makin valid butir intrumen tersebut. Jika korelasi sudah lebih besar dari 0,3 maka butir intsrumen tersebut sudah dikategorikan valid. Hasil uji instrumen di kelas XI TKJ-B menunjukkan dari 30 soal yang diujikan, ada 26 soal yang dinyatakan valid dan 4 soal dinyatakan tidak valid. Namun, hanya 20 soal yang diambil sebagai intrumen penelitian untuk soal pre-test dan posttest.

Realibitas tes pada penelitian ini menggunakan Kuder Richardson - 20 (KR20) dengan kriteria koefisien korelasi berada antara 0-1. Suatu instrumen penilaian dikatakan reliabel jika koefisien korelasinya $\geq 0,6$. Kalau koefisien korelasinya makin tinggi, maka makin reliabel instrumen tersebut, begitu pula sebaliknya. Dari perhitungan reliabilitas diperoleh besaran $r_{\text {hit }}$ adalah 0,906. Hal ini berarti bahwa $r_{\text {hi }} \geq 0,6$. Dengan demikian, soal dinyatakan reliable. 
Tabel 1. Kisi-Kisi Tes Hasil Belajar

\begin{tabular}{|c|c|c|c|c|c|c|c|c|}
\hline \multirow{2}{*}{ No } & \multirow{2}{*}{ Indikator } & \multicolumn{6}{|c|}{ Tingkat Kemampuan Kognitif } & \multirow{2}{*}{$\begin{array}{c}\text { Jumlah } \\
\text { Soal }\end{array}$} \\
\hline & & $\mathrm{C} 1$ & $\mathrm{C} 2$ & $\mathrm{C} 3$ & $\mathrm{C} 4$ & $\mathrm{C} 5$ & C6 & \\
\hline 1. & $\begin{array}{l}\text { Mengidentifikasi dampak politik, budaya, } \\
\text { sosial, ekonomi dan pendidikan pada masa } \\
\text { penjajahan bangsa Eropa dan Jepang }\end{array}$ & 1, & $\begin{array}{l}10, \\
19\end{array}$ & $\begin{array}{l}3 \\
4, \\
9\end{array}$ & $\begin{array}{l}2, \\
5, \\
11, \\
18, \\
20\end{array}$ & $\begin{array}{c}6, \\
13, \\
16\end{array}$ & & 14 \\
\hline 2. & $\begin{array}{l}\text { Menganalisis dampak politik, budaya, sosial, } \\
\text { ekonomi dan pendidikan pada masa } \\
\text { penjajahan bangsa Eropa dan Jepang yang } \\
\text { masih berpengaruh dalam kehidupan bangsa } \\
\text { Indonesia masa kini }\end{array}$ & & & $\begin{array}{l}15, \\
17\end{array}$ & 7 & & $\begin{array}{c}8, \\
12 \\
14\end{array}$ & 6 \\
\hline 3. & $\begin{array}{l}\text { Keadaan pendidikan, ekonomi, sosial, politik } \\
\text { dan ekonomi saat ini }\end{array}$ & 25 & 24 & $\begin{array}{l}28, \\
29\end{array}$ & $\begin{array}{l}22, \\
23, \\
26, \\
27\end{array}$ & 30 & 21 & 10 \\
\hline & Jumlah & 2 & 3 & 7 & 10 & 4 & 4 & 30 \\
\hline
\end{tabular}

Analisis tingkat kesukaran tes digunakan untuk mengetahui tes yang dipakai termasuk kategori tes yang mudah, sedang ataupun sukar. Dari hasil perhitungan diketahui bahwa skor tingkat kesukaran soal untuk nomor 1 adalah 0,71 yang tergolong dalam kategori mudah. Untuk total keseluruhan soal ada 5 soal yang sukar, 18 soal sedang dan 7 soal mudah. Daya pembeda soal adalah kemampuan soal untuk membedakan antara siswa yang pandai dan kurang pandai. Berdasarkan hasil perhitungan, diketahui nilai daya beda soal untuk nomor 1 adalah 0,57 yang tergolong pada kategori baik. Berdasarkan hasil uji daya beda soal terdapat 2 soal yang tidak baik, 3 soal yang jelak, 2 soal cukup baik, 22 soal yang baik dan 1 soal sangat baik.

\section{HASIL DAN PEMBAHASAN}

Penelitian ini mengambil 2 kelas sebagai sampel. Kelas yang menjadi sampel adalah kelas X TKJ-B (36 siswa) sebagai kelas eksperimen dan kelas X RPL (36 siswa) sebagai kelas kontrol. Kelas eksperimen diberi perlakuan dengan menggunakan pendekatan pembelajaran kontekstual berbasis berpikir kritis, sedangkan kelas kontrol diberikan perlakuan menggunakan model konvensional. Data nilai pre-test siswa pada kelas eksperimen dan kelas kontrol dapat dilihat pada tabel 2.

Dari 36 siswa di kelas eksperimen, jumlah siswa yang mendapat nilai 25 ada 2 orang, nilai 30 ada 4 orang, nilai 35 ada 6 orang, nilai 40 ada 5 orang, nilai 45 ada 7 orang, nilai 50 ada 4 orang, nilai 55 ada 4 orang dan nilai 60 ada 4 orang. Pada kelas kontrol yang berjumlah 36 siswa, jumlah siswa yang memperoleh nilai 30 ada 3 orang, nilai 35 ada 5 orang, nilai 40 ada 6 orang, nilai 45 ada 7 orang, nilai 50 ada 8 orang dan nilai 55 ada 7 orang. Perolehan nilai pre-test siswa dapat dilihat lebih jelas pada gambar 1 .

Sementara itu, data nilai post-test kelas eksperimen dan kelas kontrol dapat dilihat pada tabel 3. Dari 36 siswa di kelas eksperimen, siswa yang memperoleh nilai 75 berjumlah 6 orang, nilai 80 ada 6 orang, nilai 85 ada 10 orang, 90 ada 8 orang, 90 ada 8 orang dan nilai 95 ada 6 orang. Pada kelas kontrol, siswa yang mendapat nilai 60 ada 5 orang, nilai 65 ada 5 orang, nilai 70 ada 8 orang, nilai 75 ada 7 orang, nilai 80 ada 6 orang dan nilai 85 ada 5 orang. Penjabaran nilai post-test siswa dapat dilihat pada gambar 2 . 
Tabel 2. Hasil Pre-Test Kelas Eksperimen dan Kelas Kontrol

\begin{tabular}{|c|c|c|c|c|c|c|c|}
\hline \multicolumn{4}{|c|}{ Pre-Test Kelas Eksperimen } & \multicolumn{4}{c|}{ Pre-Test Kelas Kontrol } \\
\hline Nilai & F & FK & Persentase (\%) & Nilai & F & FK & Persentase (\%) \\
\hline 25 & 2 & 2 & 5,56 & 25 & - & - & - \\
\hline 30 & 4 & 6 & 11,11 & 30 & 3 & 3 & 8,33 \\
\hline 35 & 6 & 12 & 16,67 & 35 & 5 & 8 & 13,89 \\
\hline 40 & 5 & 17 & 13,89 & 40 & 6 & 14 & 16,67 \\
\hline 45 & 7 & 24 & 19,44 & 45 & 7 & 21 & 19,44 \\
\hline 50 & 4 & 28 & 11,11 & 50 & 8 & 29 & 22,22 \\
\hline 55 & 4 & 32 & 11,11 & 55 & 7 & 36 & 19,44 \\
\hline 60 & 4 & 36 & 11,11 & 60 & - & - & - \\
\hline Jumlah & 36 & & 100,00 & Jumlah & 36 & & 100,00 \\
\hline
\end{tabular}

Gambar 1. Grafik Perolehan Nilai Pre-Test Kelas Eksperimen dan Kelas Kontrol

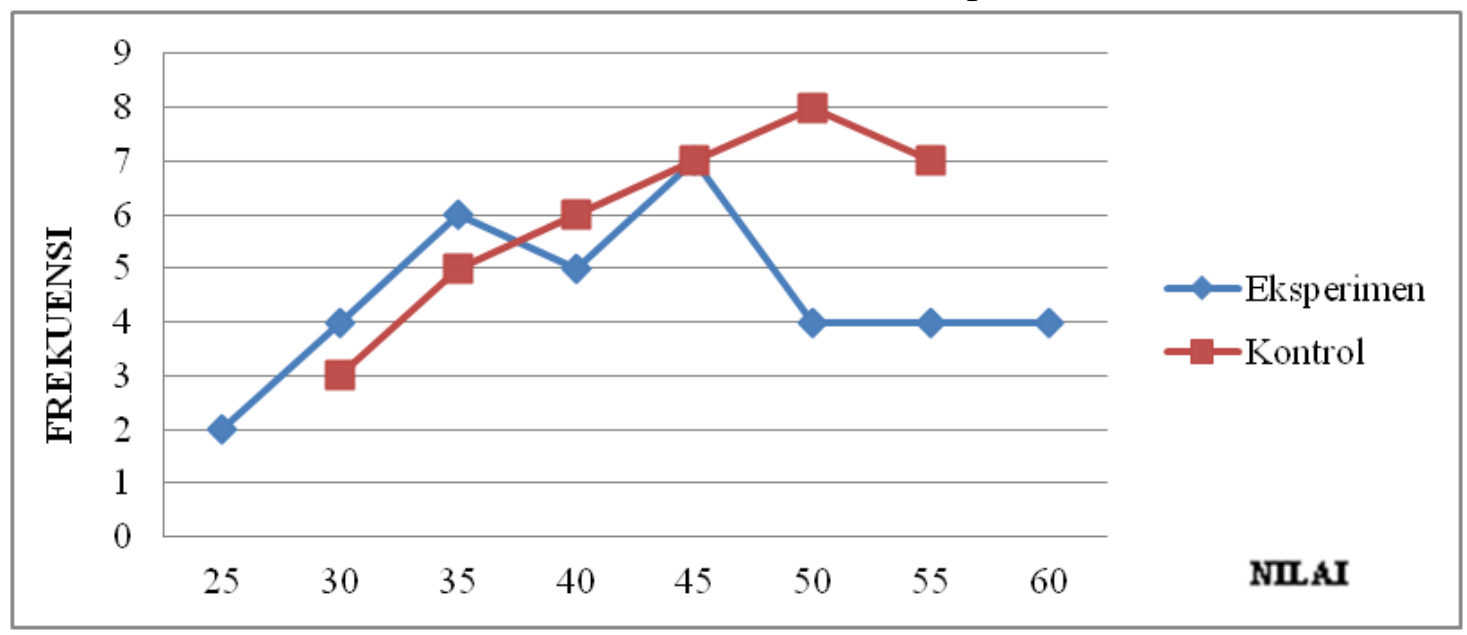

Tabel 3. Hasil Post-Test Kelas Eksperimen dan Kelas Kontrol

\begin{tabular}{|c|c|c|c|c|c|c|c|}
\hline \multicolumn{4}{|c|}{ Post-Test Kelas Eksperimen } & \multicolumn{4}{c|}{ Post-Test Kelas Kontrol } \\
\hline Nilai & F & FK & Persentase (\%) & Nilai & F & FK & Persentase (\%) \\
\hline 60 & - & - & - & 60 & 5 & 5 & 13,89 \\
\hline 65 & - & - & - & 65 & 5 & 10 & 13,89 \\
\hline 70 & - & - & - & 70 & 8 & 18 & 22,22 \\
\hline 75 & 6 & 6 & 16,67 & 75 & 7 & 25 & 19,44 \\
\hline 80 & 6 & 12 & 16,67 & 80 & 6 & 31 & 16,67 \\
\hline 85 & 10 & 22 & 27,78 & 85 & 5 & 36 & 13,89 \\
\hline 90 & 8 & 30 & 22,22 & 90 & - & - & - \\
\hline 95 & 6 & 36 & 16,67 & 95 & - & - & - \\
\hline Jumlah & 36 & & 100,00 & Jumlah & 36 & & 100,00 \\
\hline
\end{tabular}


Gambar 2. Grafik Perolehan Nilai Post-Test Kelas Eksperimen dan Kelas Kontrol

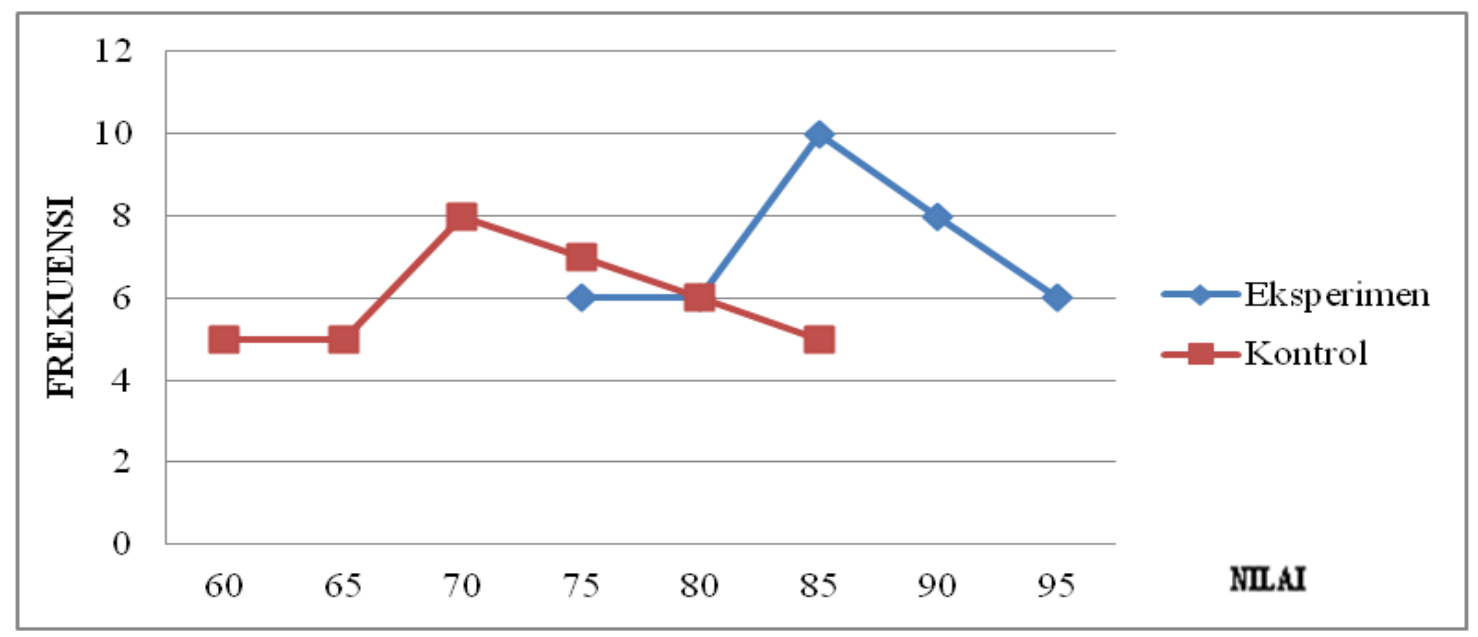

Dari hasil pre-test dan post-test pada kelas eksperimen dan kelas kontrol diperoleh data nilai rata-rata, standar deviasi dan varian yang dapat dilihat pada tabel 4. Nilai rata-rata pre-test untuk kelas eksperimen adalah 43,19, nilai standar deviasinya 10,29 dan variannya 105,93. Untuk nilai rata-rata post-test kelas eksperimen terjadi peningkatan mencapai 85,28 , sedangkan nilai standar deviasinya 6,65 dan variannya 44,21. Sementara itu, nilai rata-rata pre-test untuk kelas kontrol adalah 44,58, nilai standar deviasinya 7,96 dan variannya 63,39 . Untuk nilai rata-rata post-test kelas kontrol terjadi peningkatan menjadi 72,64. Begitu juga dengan nilai standar deviasinya, meningkat menjadi 8,06 dan variannya 64,98 .

Teknik analisis data menggunakan uji statistik yang memiliki beberapa persyaratan, seperti uji normalitas, uji homogenitas dan uji kesamaan rata-rata. Pengujian ini dilakukan dengan mengunakan uji Lieliefors (L). Uji normalitas data-data sampel dengan kriteria $\mathrm{L}_{\text {hitung }}<\mathrm{L}_{\text {tabel }}$ pada taraf signifikasi $\alpha=0,05$. Tabel 5 menunjukkan hasil uji normalistas untuk kedua kelas, yaitu nilai pre-test dan post-test kelas eksperimen berdistribusi normal dan begitu juga dengan nilai pre-test dan post-test kelas eksperimen dapat dikategorikan berdistribusi normal karena $\mathrm{L}_{\text {hitung }}<\mathrm{L}_{\text {tabel. }}$.
Untuk menguji perbedaan yang signifikan hasil belajar siswa perlu diketahui apakah kedua sampel berasal dari varian yang homogeny. Oleh karenanya, perlu dilakukan uji kesamaan varians dengan menggunakan uji Fisher (uji F). Dari hasil pre-test dan pos-tes kelas eksperimen dan kelas kontrol dilakukan pengujian $\mathrm{F}_{\text {hitung }}<\mathrm{F}_{\text {tabel }}$ untuk diterima hipotesis nol sehingga dapat dinyatakan bahwa sampel memiliki varians yang homogen. Jika menunjukkan hasil yang berbeda, maka varians tidak homogen. Tabel 6 menunjukkan hasil dari uji homogenitas dari kedua kelas. Hasil pre-test dan post-test kelas eksperimen bersifat homogen. Begitu juga dengan kelas kontrol, hasilnya bersifat homogen karena sesuai dengan kriteria $F_{\text {hit }}<F_{\text {tab. }}$.

Sementera itu, tabel 7 menunjukkan ringkasan perhitungan uji hipotesis untuk kemampuan pre-test kelas eksperimen dan kelas kontrol. Adapun kriteria hipotesisnya, jika $\mathrm{T}_{\text {hit }}<$ $\mathrm{T}_{\text {tab }}$ maka $\mathrm{H} 0$ diterima dan $\mathrm{Ha}$ ditolak. Berdasarkan kriteria itu, hasil uji hipotesis untuk pre-test kelas eksperimen dan kelas kontrol adalah $\mathrm{T}_{\text {hit }}-0,63<\mathrm{T}_{\text {tab }} 2,003$, maka H0 diterima. Dengan demikian, dapat dikatakan bahwa pengetahuan awal siswa di antara kedua kelas adalah sama.

Tabel 8 menunjukkan ringkasan perhitungan uji hipotesis untuk kemampuan post-test 
kelas eksperimen dan kelas kontrol. Adapun kriteria hipotesisnya, jika $\mathrm{T}_{\text {hit }}>\mathrm{T}_{\text {tab }}$ maka Ha diterima dan $\mathrm{HO}$ ditolak. Berdasarkan kriteria itu, hasil uji hipotesis untuk hasil post-test kelas eksperimen dan kelas kontrol adalah $\mathrm{T}_{\text {hit }}$
$7,14<\mathrm{T}_{\text {tab }}$ 1,668 maka Ha diterima. Artinya, terdapat perbedaan hasil belajar yang signifikan di antara kedua kelas. Hasil belajar kelas eksperimen lebih tinggi daripada kelas kontrol.

Tabel 4. Nilai Rata-Rata, Standar, Deviasi dan Varian

\begin{tabular}{|c|l|c|c|c|c|}
\hline \multirow{2}{*}{ No } & \multirow{2}{*}{ Keterangan } & \multicolumn{2}{|c|}{ Kelas Eksperimen } & \multicolumn{2}{c|}{ Kelas Kontrol } \\
\cline { 3 - 6 } & & Pre-test & Post-test & Pre-test & Post-test \\
\hline 1 & Rata-rata & 43,19 & 85,28 & 44,58 & 72,64 \\
\hline 2 & Standar Deviasi & 10,29 & 6,65 & 7,96 & 8,06 \\
\hline 3 & Varians & 105,93 & 44,21 & 63,39 & 64,98 \\
\hline
\end{tabular}

Tabel 5. Hasil Uji Normalitas Kelas Eksperimen dan Kelas Kontrol

\begin{tabular}{|c|c|c|c|c|c|}
\hline \multirow[b]{2}{*}{ No } & \multirow{2}{*}{ Statistik } & \multicolumn{2}{|c|}{ Kelas Eksperimen } & \multicolumn{2}{|c|}{ Kelas Kontrol } \\
\hline & & Pre-test & Post-test & Pre-test & Post-test \\
\hline 1 & $\mathrm{~N}$ & 36 & 36 & 36 & 36 \\
\hline 2 & $\overline{\bar{X}}$ & 43,19 & 85,28 & 44,58 & 7,96 \\
\hline 3 & $\mathrm{~S}$ & 10,29 & 6,65 & 72,64 & 8,06 \\
\hline 4 & $\mathrm{~L}_{\text {hitung }}$ & 0,1214 & 0,1271 & 0,1079 & 0,1255 \\
\hline 5 & $\begin{array}{l}\mathrm{L}_{\text {tabel }} \\
\end{array}$ & 0,1476 & 0,1476 & 0,1476 & 0,1476 \\
\hline & Kesimpulan & $\begin{array}{c}\text { Berdistribusi } \\
\text { Normal }\end{array}$ & $\begin{array}{c}\text { Berdistribusi } \\
\text { Normal }\end{array}$ & $\begin{array}{l}\text { Berdistribusi } \\
\text { Normal }\end{array}$ & $\begin{array}{l}\text { Berdistribusi } \\
\text { Normal }\end{array}$ \\
\hline
\end{tabular}

Tabel 6. Hasil Uji Homogenitas Kelas Eksperimen dan Kelas Kontrol

\begin{tabular}{|c|l|c|c|c|c|}
\hline No & \multicolumn{1}{|c|}{ Data Kelas } & Vatrian & $\mathrm{F}_{\text {hitung }}$ & $\mathrm{F}_{\text {tabel }}$ & Kesimpulan \\
\hline 1 & Pre-test Kelas Eksperimen & 105,93 & 1,671 & 1,89 & Homogen \\
\hline 2 & Pre-test Kelas Kontrol & 63,39 & 1,671 & 1,89 & Homogen \\
\hline 3 & Post-test Kelas Eksperimen & 44,21 & 1,470 & 1,89 & Homogen \\
\hline 4 & Post-test Kelas Kontrol & 64,98 & 1,470 & 1,89 & Homogen \\
\hline
\end{tabular}

Tabel 7. Hasil Uji Hipotesis Pre-Test Siswa

\begin{tabular}{|c|l|c|c|c|c|}
\hline No & \multicolumn{1}{|c|}{ Data Kelas } & Nilai Rata-Rata & $\mathrm{T}_{\text {hitung }}$ & $\mathrm{T}_{\text {tabel }}$ & Kesimpulan \\
\hline 1 & Kelas Eksperimen & 43,19 & \multirow{2}{*}{$-0,63$} & 2,003333 & $\begin{array}{l}\text { Pengetahuan awal siswa } \\
\text { antara kedua kelas sama }\end{array}$ \\
\hline 2 & Kelas Kontrol & 44,58 & -60 &
\end{tabular}

Tabel 8. Hasil Uji Hipotesis Post-Test Siswa

\begin{tabular}{|c|l|c|c|c|l|}
\hline No & \multicolumn{1}{|c|}{ Data Kelas } & $\begin{array}{c}\text { Nilai Rata- } \\
\text { Rata }\end{array}$ & $\mathrm{T}_{\text {hitung }}$ & $\mathrm{T}_{\text {tabel }}$ & \multicolumn{1}{c|}{ Kesimpulan } \\
\hline 1 & Kelas Eksperimen & 85,28 & \multirow{2}{*}{7,14} & 1,668 & $\begin{array}{l}\text { Hasil belajar kelas eksperimen lebih } \\
\text { tinggi daripada kelas kontrol }\end{array}$ \\
\hline 2 & Kelas Kontrol & 72,64 & &
\end{tabular}


Pada saat pendekatan pembelajaran kontekstual berbasis berpikir kritis diterapkan di kelas eksperimen, ada beberapa kelebihan yang diterlihat dibandingkan dengan kelas kontrol yang masih menggunakan model pembelajaran konvensional. Proses pembelajaran dengan pendekatan kontekstual yang berlangsung di kelas eksperimen membuat hampir seluruh siswa berperan aktif dalam kegiatan diskusi. Mereka aktif mencari data terkait dengan materi pelajaran dari berbagai sumber, seperti buku paket, koran dan internet. Bahkan kejadian yang mereka alami juga dijadikan sumber belajar. Sewaktu kelompok mempersentasikan hasil pekerjaannya sering terjadi perdebatan pendapat antar-kelompok. Siswa menggali sendiri pengetahuannya dari sumber yang mereka kumpulkan dan selalu mengaitkan fenomena-fenomena yang berkaitan dengan materi pelajaran, seperti tentang pendidikan, ekonomi dan hal lainnya. Di akhir pembelajaran, siswa selalu menyimpulkan materi apa yang telah mereka dapatkan dan menanyakan hal yang kurang mereka pahami kepada guru. Dengan demikian, penerapan model pembelajaran kontekstual telah membuat siswa mengalami proses berpikir kritis tanpa mereka sadari.

Selanjutnya, saat menjawab soal post-test terdapat perbedaan jawaban yang signifikan di antara siswa kelas eksperimen dan siswa kelas kontrol. Hal ini terlihat dari nilai yang mereka dapatkan. Siswa di kelas eksperimen memperoleh nilai yang lebih tinggi daripada siswa kelas kontrol. Ada beberapa soal post-test yang tidak mampu dijawab oleh siswa kelas kontrol. Hal ini dikarenakan muatan soal yang diberikan berkaitan dengan konteks kehidupan sekarang dan diperlukan pemikiran yang cukup kritis untuk menjawabnya. Kemampuan berpikir kritis inilah yang tidak dimiliki oleh siswa kelas kontrol sehingga mereka tidak mampu untuk menjawab soal.

Model pembelajaran konvensional diterapkan di kelas kontrol. Guru memiliki peran yang sangat penting dalam kegiatan pembelajaran yang menggunakan model konvensional.
Jika guru tidak tepat menerapkan model pembelajaran ini, maka siswa akan meresa jenuh. Kalau guru cerdas menerapkannya, maka siswa juga bisa tertarik untuk belajar. Ketika model pembelajaran konvensional diterapkan di kelas kontrol, sebagian siswa terlibat aktif dalam proses pembelajaran. Bahkan saat guru menjelaskan, sering kali diringi dengan kegiatan diskusi dan tanya jawab dengan siswa. Meskipun begitu, pengetahuan yang diperoleh siswa kelas kontrol berbeda dengan siswa kelas eksperimen. Pengetahuan siswa kelas kontrol hanya sebatas materi pelajaran yang ada di buku paket, sedangkan siswa kelas eksperimen mampu mengaitkan materi pelajaran dengan kehidupan nyata mereka.

Perbedaan model pembelajaran yang diterapkan di kelas eksperimen dan kelas kontrol telah membuat hasil belajar sejarah siswa juga berbeda. Siswa kelas eksperimen yang menjalani proses pembelajaran dengan pendekatan kontekstual berbasis berpikir kritis memperoleh hasil belajar yang lebih tinggi dibandingkan dengan siswa kelas kontrol yang menjalani kegiatan pembelajaran dengan model konvensional. Siswa di kelas eksperimen terlihat lebih aktif dalam mengemukakan pendapat saat kegiatan diskusi. Bahkan mereka juga terbiasa berpikir kritis karena mereka dituntut untuk mengaitkan materi pelajaran dengan kehidupan nyata. Dengan begitu, siswa di kelas eksperimen dapat mengambil manfaat dari belajar sejarah bagi kehidupan sehari-harinya. Sementara itu, penerapan model pembelajaran konvensional di kelas kontrol hanya membuat sebagian kecil siswa terlibat aktif dalam kegiatan pembelajaran.

\section{SIMPULAN}

Penerapan pendekatan kontektual berbasis berpikir kritis dalam proses pembelajaran sejarah di SMK Negeri 1 Lubuk Pakam ternyata dapat membuat hasil belajar sejarah siswa mengalami peningkatan. Hal ini dapat dilihat dari perbandingan hasil belajar antara siswa kelas $\mathrm{X}$ jurusan TKJ-B yang memperoleh pendekatakan pem- 
belajaran kontekstual berbasis berpikir kritis dengan siswa kelas X RPL yang memperoleh model pembelajaran konvensional. Siswa kelas $\mathrm{X}$ TKJ-B yang menjalani proses pembelajaran dengan menggunakan pendekatan kontekstual berbasis berpikir kritis memperoleh hasil belajar yang cukup tinggi, dengan nilai rata-rata mencapai 85,28. Sementara itu, siswa kelas X RPL yang menjalani proses pembelajaran dengan model konvensional hanya mendapat nilai ratarata 72,64 .

Siswa kelas X TKJ-B terlibat lebih aktif dalam proses pembelajaran. Bahkan mereka tidak hanya mendapat pengetahuan tentang materi sejarah yang mereka pelajari, tetapi juga dapat mengambil manfaat dari materi tersebut. Hal ini dikarenakan siswa kelas $\mathrm{X}$ TKJ-B mampu mengaitkan materi pelajaran dengan kehidupan sehari-hari. Sementara itu, proses pembelajaran dengan model konvensional di kelas X RPL cenderung membosankan karena hanya sedikit siswa yang aktif dalam kegiatan pembelajaran. Pengetahuan yang diperoleh siswa kelas X RPL hanya sebatas materi pelajaran yang ada di buku paket.

\section{REFERENSI}

Ali, R. M. (2005). Pengantar Ilmu Sejarah Indonesia. Yogyakarta: LKiS.

Fisher, A. (2009). Berpikir Kritis; Sebuah Pengantar. Jakarta: Erlangga.

Isjoni. (2007). Pembelajaran Sejarah pada Satuan Pendidikan. Bandung: Alfabeta.

Kochhar, S. K. (2008). Teaching of History (Pembelajaran Sejarah). Jakarta: Grasindo.

Subakti, Y. R. (2010). Paradigma Pembelajaran Sejarah Berbasis Konstruktivisme. Jurnal SPPS, 24(1).

Sukmadinata, N. S. (2013). Metode Penelitian Pendidikan. Bandung: Remaja Rosdakarya. 